\title{
Long-term moderate intervention with $n$-3 long-chain PUFA-supplemented dairy products: effects on pathophysiological biomarkers in patients with rheumatoid arthritis
}

\author{
Christine Dawczynski ${ }^{1}$, Rainer Schubert ${ }^{1}$, Gert Hein $^{2}$, Andreas Müller ${ }^{2}$, Thorsten Eidner ${ }^{2}$, \\ Heinz Vogelsang ${ }^{3}$, Samar Basu ${ }^{4}$ and Gerhard Jahreis ${ }^{1 *}$ \\ ${ }^{1}$ Department of Nutritional Physiology, Institute of Nutrition, Friedrich Schiller University of Jena, Dornburger Str. 24, D-07743 \\ Jena, Germany \\ ${ }^{2}$ Department of Internal Medicine III, Friedrich Schiller University of Jena, Erlanger Allee 101, D-07747 Jena, Germany \\ ${ }^{3}$ Department of Clinical Medicine and Laboratory Diagnostics, Friedrich Schiller University of Jena, Erlanger Allee 101, D-07747 \\ Jena, Germany \\ ${ }^{4}$ Division of Clinical Nutrition and Metabolism, Department of Public Health and Caring Sciences, Faculty of Medicine, Uppsala \\ University, Uppsala, Sweden \\ (Received 22 April 2008 - Revised 23 July 2008 - Accepted 1 September 2008 - First published online 27 February 2009)
}

\begin{abstract}
$n$-3 long-chain PUFA (n-3 LC-PUFA) may improve cardiovascular and inflammatory diseases. The effects of $n$-3 LC-PUFA-supplemented dairy products on inflammation and immunological parameters, biomarkers of oxidative stress, serum lipids, and on disease activity were determined in patients with rheumatoid arthritis (RA). Forty-five subjects (forty-three females and two males) were randomly divided into two groups in a double-blind, placebo-controlled cross-over study. Both groups received placebo or verum products consecutively for 3 months with a 2-month washout phase between the two periods. Blood samples were taken at the beginning and at the end of each period. The dairy products generally improved serum lipids by increasing HDL and lowering lipoprotein a. The $n-3$ LC-PUFA supplements act to lower TAG. Additionally, a decreased lipopolysaccharide-stimulated cylo-oxygenase-2 expression was found in patients who had consumed the enriched dairy products. The majority of the $\mathrm{CD}$ analysed were not influenced, although $n$-3 LC-PUFA did suppress the immune response as lymphocytes and monocytes were found to be significantly decreased. The $n$-3 LC-PUFA did not increase the biomarkers of oxidative stress such as 8 -iso-PGF $2 \alpha$ and 15 -keto-dihydro PGF $2 \alpha$, and DNA damage like 7,8-dihydro-8-oxo-2'-deoxyguanosine. The long-term consumption of dairy products $(2 \times 12$ weeks $)$ diminished the excretion of hydroxypyridinium crosslinks, and favoured the diastolic blood pressure. The consumption of moderate doses of $n$ - 3 LC-PUFA in combination with dairy products did not improve the disease activity. However, there is evidence of cardioprotective effects. Furthermore, the long-term consumption of dairy products acts against the cartilage and bone destruction in RA.
\end{abstract}

Rheumatoid arthritis: $n$-3 Long-chain PUFA: Dairy products: Cardiovascular risk

During the past few years, numerous studies and reviews have underlined the beneficial effects of $n-3$ long-chain PUFA ( $n-3$ LC-PUFA) found in fish and fish oils in the prevention and management of both cardiovascular and chronic inflammatory diseases, such as rheumatoid arthritis (RA) ${ }^{(1-5)}$.

$n$-3 LC-PUFA, e.g. EPA (20:5n-3) and DHA (22:6n-3), as well as $n-6$ PUFA, e.g. arachidonic acid (AA, 20:4n-6), are present in cell phospholipids (PL). These fatty acids (FA) are involved in many physiological processes through their influence on membrane fluidity, eicosanoid synthesis, receptor affinity, cell signalling and gene expression ${ }^{(2,3,6-8)}$. The eicosanoids derived from AA are biologically active in very small quantities; however, in larger concentrations, they may contribute to thrombus formation, the development of atheromas, as well as allergic and inflammatory diseases ${ }^{(9)}$. On supplementing the diet with $n$-3 LC-PUFA, the concentrations of $n-3$ FA in individual tissues increased, whereas that of AA decreased $^{(7,10)}$. Additionally, consumption of $n-3$ LC-PUFA may lead to a reduction in the production of pro-inflammatory cytokines and cartilage-degrading enzymes ${ }^{(11)}$. Hence, the intake of FA can directly modulate the synthesis and action of regulatory eicosanoids and cytokines.

RA characterised by an autoimmune inflammation, involving both small and large joints, is mediated by an exaggerated production of eicosanoids and cytokines. The chronic inflammation process in the affected joints leads to the

Abbreviations: AA, arachidonic acid; ARA, American Rheumatism Association; CE, chotesteryl esters; COX, cyclo-oxygenase; Cr, creatinine; DAS28, disease activity score; Dpyr, deoxypyridinoline; FA, fatty acids; 8-oxodG, 7,8-dihydro-8-oxo-2'-deoxyguanosine; PL, phospholipids; Pyr, pyridinoline; RA, rheumatoid arthritis.

* Corresponding author: Dr Gerhard Jahreis, fax +49 3641949 612, email gerhard.jahreis@uni-jena.de 
formation of degenerative and erosive lesions in cartilage and bones. Improvements in the clinical and immunological parameters of RA via $n$-3 LC-PUFA consumption have been shown in several intervention studies ${ }^{(3,12-14)}$.

In the present study, dairy products were enriched with $n$-3 LC-PUFA. Conventional dairy products are poor in LC-PUFA, although they are a source of anti-inflammatory effectuating conjugated linoleic acids $(18: 2 n-6)^{(15,16)}$ and SCFA. Dairy products are, however, rich in oleic acid (18: $1 n-9)$, although they contain only marginal concentrations of AA. Moreover, dairy products are the most important source of bioavailable calcium.

The aim of the present long-term study with RA patients was to compound the positive effects of dairy products (yoghurt, cheese and butter) with moderate doses of $n$ - 3 LC-PUFA on the risk factors of CVD (serum lipids and inflammation parameters), immune biomarkers, collagen crosslinks, markers of oxidative stress, and on the disease activity of RA.

\section{Subjects and methods}

\section{Subjects}

Forty-five patients (forty-three females and two males) with RA, diagnosed according to the 1987 revised criteria of the American Rheumatism Association, were included in the study after giving their informed consent.

Patients receiving either non-steroidal anti-inflammatory drugs or corticosteroids $(\leq 15 \mathrm{mg} / \mathrm{d}$ ) or both were eligible if the dosage had been stable for at least 4 weeks before day 1 of the study and remained below this limit throughout the study. Those on disease-modifying antirheumatic drugs had to be on a constant dosage for at least 8 weeks before and throughout the study. Subjects diagnosed with gastrointestinal or metabolic diseases, and alcohol abuse, those taking dietary supplements (e.g. fish oil capsules), and with known food allergy or food intolerance were excluded.

Patients were withdrawn from the study at any time after enrolment for the following reasons: patient's request; acquisition of a serious infection; an inadequate control of the arthritic symptoms $(\geq 50 \%$ increase in the number of swollen or tender joints); the reinstitution of therapy with disease-modifying antirheumatic drugs; if the patient compliance with the study protocol was doubtful. The study protocol was approved by the Ethical Committee of the Friedrich Schiller University of Jena.

\section{Study design and diet}

The randomised, double-blind, placebo-controlled cross-over study consisted of two 12-week investigation periods and an 8-week washout phase between the two periods (Fig. 1). Patients received approximately $40 \mathrm{~g}$ fat in the form of $200 \mathrm{~g}$ yoghurt with $3.8 \%$ fat, $30 \mathrm{~g}$ cheese with about $50 \%$ fat in the DM and $20-30 \mathrm{~g}$ butter, daily. The milk fat was partially exchanged by special oils such as fish, rapeseed and Dracocephalum ibericum oil containing high concentrations of EPA, DHA and $\alpha$-linolenic acid $(18: 3 n-3)$. The daily dose of $n-3$ FA, consisting of $1.1 \mathrm{~g} \alpha$-linolenic acid, $0.7 \mathrm{~g}$ EPA, $0.1 \mathrm{~g}$ DPA and $0.4 \mathrm{~g}$ DHA, amounted to $2.4 \mathrm{~g}$. Commercial dairy products with comparable fat contents were used as a placebo.
The intake of AA was about $50 \mathrm{mg} / \mathrm{d}$ through the intervention products and about $70 \mathrm{mg} / \mathrm{d}$ through the control products. All products used in the study were offered in neutral packaging.

Patients had to fill a nutrition diary in both study periods, where they documented the daily consumption (kind and amount) of meat, meat products, fish, fish products, oils and fats.

The following criteria were assessed both at the beginning and at the end of each period: body weight; blood pressure; duration of morning stiffness as estimated by the patients; the disease activity score (DAS28).

\section{Blood and urine collection}

Between 07.30 and 08.00 hours, fasting blood samples were drawn by venepuncture into evacuated tubes (Sarstedt ${ }^{\circledR}$ ). The venous blood was collected into one citrate tube, two evacuated serum tubes ( 5 and $10 \mathrm{ml}$ ), one evacuated tube $(10 \mathrm{ml})$ containing $\mathrm{K}_{3}$-EDTA $(1 \mathrm{mg} / \mathrm{ml})$ and one evacuated tube $(10 \mathrm{ml})$ containing Li-heparin.

The blood samples were processed as follows. After plasma and platelets were separated by centrifugation $(10 \mathrm{~min}$, $2000 \mathrm{rpm}$ ), plasma and serum samples were placed in individual tubes and stored at $-80^{\circ} \mathrm{C}$ until analysis. The C-reactive protein, alkaline phosphatase, $\gamma$-glutamyltransferase concentrations and cyclo-oxygenase (COX) expression were analysed in plasma. For serum, total cholesterol, HDL, LDL, TAG and lipoprotein a levels were evaluated.

Urine samples were collected during the day before blood samples were taken (Fig. 1). The morning urine from the first day was not kept, but samples of urine from the rest of the day until the morning urine on the next day ( $24 \mathrm{~h}$ urine collection) were collected in a special $24 \mathrm{~h}$ urine collection tank (10 ml; Sarstedt ${ }^{\circledR}$, Nümbrecht, Germany).

The samples were placed in urine monovettes (Sarstedt ${ }^{\circledR}$ ) and stored at $-80^{\circ} \mathrm{C}$ until analysis. The $24 \mathrm{~h}$ urine was tested for collagen crosslinks, 7,8-dihydro-8-oxo-2'-deoxyguanosine (8-oxodG), 8-iso-PGF ${ }_{2 \alpha}$, 15-keto-dihydro-PGF $\mathrm{P}_{2 \alpha}$ and creatinine $(\mathrm{Cr})$.

\section{Lipid extraction and fatty acid analysis}

Plasma lipids were extracted by employing a methanol-chloroform mixture according to the method of Bligh \& Dyer ${ }^{(17)}$. PL and cholesteryl esters (CE) were isolated from plasma lipid

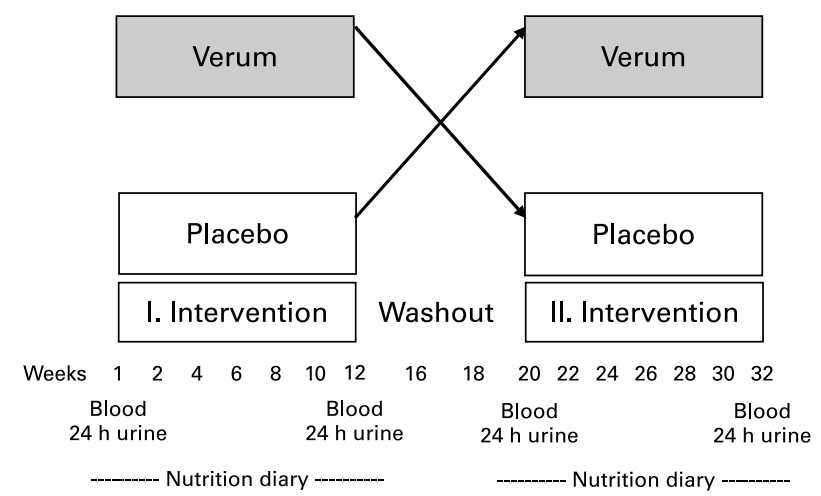

Fig. 1. Design of the clinical study. 
extracts by TLC with the use of hexane-diethyl ether-acetic acid (85:15:0·2, by vol.). Furthermore, an acid-catalysed methylation was performed using anhydrous $\mathrm{HCl}-$ methanol $(5 \%$ w/v; Supelco, Bellefonte, PA, USA). The resulting fatty acid methyl esters were isolated by means of TLC. The FA analysis was conducted via GC (GC-17 V3; Shimadzu, Tokyo, Japan) equipped with an autosampler and a flame ionisation detector. FA ranging from four to twenty-five carbon atoms in length, as well as the total conjugated linoleic acids, were determined using a fused silica capillary column (CP Select for fatty acid methyl esters (Chrompak, Walton-on-Thames, UK), $200 \mathrm{~m} \times 0.25 \mathrm{~mm} \times 0.25 \mu \mathrm{m}$; Shimadzu, Canby, OR, USA). The FA concentrations were expressed as a percentage of the total area of all FA peaks (percentage of total fatty acid methyl esters).

\section{Blood and urinary parameters}

The erythrocyte sedimentation rate was measured using the Westergren technique. C-reactive protein was quantified by means of the turbidimetric immunoassay on the Synchron LX $^{\circledR} 20$ system (Beckman Coulter, Fullerton, CA, USA). Serum total cholesterol, HDL, LDL, TAG, Cr, the activity of $\gamma$-glutamyltransferase and alkaline phosphatase were ascertained by enzymatic methods employing commercially available kits (Beckmann, Krefeld, Germany) and using the autoanalyser Synchron LX systems (Beckman Coulter), according to the methods of the International Federation of Clinical Chemistry and Laboratory Medicine.

The WBC counts were determined using the haematology analyser (KX-21; Sysmex). The immunophenotyping of leucocytes was performed by flow cytometry. The lymphocytes, monocytes, granulocytes and lymphocyte subpopulations (CD3+, $\mathrm{CD} 19+, \mathrm{CD} 4+, \mathrm{CD} 8+, \mathrm{NK}+, \mathrm{CD} 3+\mathrm{NK}+$, $\mathrm{CD} 57+, \mathrm{CD} 8+\mathrm{CD} 57+, \mathrm{CD} 25+, \mathrm{CD} 4+\mathrm{CD} 25+$ and CD3+HLA-DR+) were analysed on a flow cytometer FACScan using the SimulSET software, as described by Klein et al. ${ }^{(18)}$.

COX-1 and COX-2 expressions in whole-blood monocytes were determined by flow cytometry (FACScan ${ }^{\mathrm{TM}}$ instruments) utilising a test kit for monoclonal antibodies that detected human antigens (BD Biosciences, Heidelberg, Germany), modified according to Ruitenberg \& Waters ${ }^{(19)}$. The results were expressed as a percentage of positively stained cells (\%).

The $24 \mathrm{~h}$ urine samples were prepared for pyridinoline (Pyr) and deoxypyridinoline (Dpyr) analyses via HPLC, as described by Müller et al. ${ }^{(20)}$ and Hein et al. ${ }^{(21)}$.

A highly specific and sensitive RIA was used to determine the urinary concentrations of free 8 -iso- $\mathrm{PGF}_{2 \alpha}$ and 15-ketodihydro- $\mathrm{PGF}_{2 \alpha}{ }^{(22,23)}$.

The analysis of 8-oxodG was conducted by means of HPLC and electrochemical detection ${ }^{(24)}$. After $\mathrm{Cr}$ correction, the urinary parameters were expressed as $\mathrm{nmol} / \mathrm{mol} \mathrm{Cr}$.

\section{Statistical analysis}

The statistical assessment of the data was performed using SPSS version 14.0 (SPSS Inc., Chicago, IL, USA). A value of $P \leq 0.05$ indicates significant intra- and intergroup changes. The results are presented as means and standard deviations.
The Kolmogorov-Smirnov test was used to verify the distribution of the data.

Possible differences in the intervention or the control period as well as between the end values of the intervention and control periods were tested with repeated measurements (ANOVA). The intervention sequence of the cross-over design was considered as a covariate. The differences between the start and end values after $2 \times 12$ study weeks were analysed by means of the paired $t$ test. If the data were not normally distributed, the Wilcoxon test was used. Relationships between variables were calculated using Pearson's correlation or Kendall's tau, in case of not normally distributed data.

\section{Results}

Six patients, representing a dropout rate of $13 \%$, did not complete the study because they showed side effects due to disease-modifying antirheumatic drugs. Thirty-nine test subjects aged $57.9 \pm 10 \cdot 8$ years completed the 8-month intervention study. Of these, eleven needed an intra-articular injection of corticosteroids less than 4 weeks before blood sampling was carried out. Hence, these patients were excluded from the statistical evaluation. Furthermore, seven patients were omitted because the EPA increase in erythrocyte membranes was less than $10 \%$ after the 12 weeks of the intervention period and adherence to the protocol was doubtful. We assume that the compliance of these patients was not given and they are 'non-consumers'.

Fatty acid distribution in plasma lipids, cholesteryl esters and phospholipids

In plasma lipids, $\alpha$-linolenic acid, EPA, DPA, DHA, $n-3$ FA and $n$-3 LC-PUFA increased significantly. In addition, there was a significant decrease of the AA:EPA, AA: $n-3$ LC-PUFA as well as $n$ - 6 FA: $n-3$ FA ratios during the verum treatment (Table 1). In the control group, the concentrations of these FA were not affected. There was a low increase in the AA levels in this group. The final values of all $n-3$ LC-PUFA, the ratios, $n-3, n-6$ FA and SFA differed significantly between the verum and control periods $(P \leq 0.05)$, respectively.

In $\mathrm{CE}$, the concentrations of $\alpha$-linolenic acid, EPA, DHA, $n$-3 FA and $n$-3 LC-PUFA were increased significantly by the intervention treatment. The ratios, together with $n-6 \mathrm{FA}$, were significantly decreased by the consumption of $n-3$ LCPUFA-supplemented dairy products $(P \leq 0.05$; Table 1$)$.

In PL, the concentration of EPA and MUFA increased significantly in the intervention period. The ratios decreased by the consumption of $n$-3 LC-PUFA-supplemented diary products $(P \leq 0.05$; Table 1$)$. The increase of DPA, DHA, $n$-3 FA and $n$-3 LC-PUFA was not significant (Table 1 ).

\section{Nutrition diary}

The analysis of the nutrition diary provided information about the basal diet without consideration of the study products. There were no differences in the intake of oleic acid, AA, EPA, DHA, SFA, MUFA, PUFA, $n-3$ LC-PUFA, $n-3$ and $n-6$ PUFA, and transFA between the intervention and control periods (Table 2). The patients consumed $0 \cdot 2-0.3 \mathrm{~g} n$-3 LC-PUFA/d and $0 \cdot 8-0.9 \mathrm{~g}$ $\mathrm{AA} / \mathrm{d}$ by the intake of meat and fish during the study. 
Table 1. Fatty acid (FA) distribution in plasma lipids, cholesteryl esters (CE) and phospholipids (PL) at baseline and after a 12-week intake of $n$-3 longchain PUFA ( $n$-3 LC-PUFA)- supplemented or control dairy products†

(Mean values and standard deviations)

\begin{tabular}{|c|c|c|c|c|c|c|c|c|c|c|}
\hline \multirow{4}{*}{$\begin{array}{l}n 21 \text { (Percentage } \\
\text { of total FAME) }\end{array}$} & \multirow[b]{4}{*}{ Weeks } & \multicolumn{9}{|c|}{ Plasma lipids } \\
\hline & & \multicolumn{4}{|c|}{ Total plasma lipids } & \multirow[b]{3}{*}{$P_{\text {treatment effect }} \ddagger$} & \multirow{2}{*}{\multicolumn{2}{|c|}{$\begin{array}{c}\text { CE } \\
\text { Intervention } \\
\text { period }\end{array}$}} & \multirow{2}{*}{\multicolumn{2}{|c|}{$\begin{array}{c}\mathrm{PL} \\
\text { Intervention } \\
\text { period }\end{array}$}} \\
\hline & & $\begin{array}{l}\text { Interve } \\
\text { per }\end{array}$ & & Contrc & eriod & & & & & \\
\hline & & Mean & SD & Mean & SD & & Mean & SD & Mean & SD \\
\hline \multirow[t]{2}{*}{ ALA $18: 3 n-3$} & 0 & 0.61 & 0.21 & 0.63 & 0.31 & & 0.09 & 0.12 & 0.29 & 0.21 \\
\hline & 12 & $0.71^{*}$ & 0.21 & 0.67 & 0.50 & NS & $0.15^{\star \star *}$ & 0.12 & 0.27 & 0.12 \\
\hline \multirow[t]{2}{*}{ AA $20: 4 n-6$} & 0 & $5 \cdot 68$ & 1.40 & 5.58 & $1 \cdot 18$ & & $5 \cdot 24$ & $1 \cdot 20$ & 1.02 & 0.44 \\
\hline & 12 & 5.47 & 1.00 & 5.85 & 1.20 & NS & $5 \cdot 34$ & 1.01 & 0.91 & 0.43 \\
\hline \multirow[t]{2}{*}{ EPA $20: 5 n-3$} & 0 & 0.72 & 0.35 & 0.71 & 0.20 & & 0.89 & 0.59 & 0.21 & 0.10 \\
\hline & 12 & $1.69^{\star \star \star}$ & 0.94 & 0.84 & 0.58 & $P \leq 0.001$ & $2 \cdot 01^{\star \star *}$ & 1.24 & $0.33^{\star *}$ & 0.16 \\
\hline \multirow[t]{2}{*}{ DPA $22: 5 n-3$} & 0 & 0.39 & 0.10 & 0.40 & 0.08 & & 0.66 & 0.40 & 0.38 & 1.19 \\
\hline & 12 & $0.50^{\star \star \star}$ & 0.16 & 0.42 & 0.13 & $P \leq 0.05$ & 0.65 & 0.30 & 0.71 & 1.91 \\
\hline \multirow[t]{2}{*}{ DHA $22: 6 n-3$} & 0 & 1.35 & 0.47 & 1.35 & 0.34 & & 0.38 & 0.19 & 0.26 & 0.20 \\
\hline & 12 & $1.87^{\star \star \star}$ & 0.63 & 1.47 & 0.64 & $P \leq 0.01$ & $0.53^{* * *}$ & 0.22 & 0.35 & 0.20 \\
\hline \multirow[t]{2}{*}{ AA:EPA ratio } & 0 & 9.09 & 3.30 & 8.35 & $2 \cdot 40$ & & $7 \cdot 41$ & 3.04 & $5 \cdot 76$ & $2 \cdot 87$ \\
\hline & 12 & $4 \cdot 28^{\star \star \star}$ & 2.57 & 9.78 & 6.97 & $P \leq 0.001$ & $3 \cdot 86^{\star \star *}$ & $2 \cdot 84$ & $2 \cdot 93^{\star \star \star}$ & 1.34 \\
\hline \multirow[t]{2}{*}{$\sum n-3$ LC-PUFA } & 0 & 2.46 & 0.84 & 2.46 & 0.56 & & 1.93 & 0.88 & 0.85 & 1.31 \\
\hline & 12 & $4.06^{\star \star \star}$ & 1.65 & $2 \cdot 73$ & 1.29 & $P \leq 0.01$ & $3 \cdot 20^{* * *}$ & 1.32 & 1.39 & 1.90 \\
\hline \multirow[t]{2}{*}{ AA:n3 LC-PUFA ratio } & 0 & 2.47 & 0.66 & $2 \cdot 34$ & 0.49 & & $3 \cdot 13$ & 1.43 & $2 \cdot 11$ & 1.42 \\
\hline & 12 & $1.53^{\star \star \star}$ & 0.59 & 2.43 & 0.80 & $P \leq 0.001$ & $1.89^{\star \star}$ & 0.73 & $1 \cdot 14^{\star \star}$ & 0.70 \\
\hline \multirow[t]{2}{*}{$\sum n-3 \mathrm{FA}$} & 0 & 3.11 & 0.94 & $3 \cdot 13$ & 0.68 & & 2.07 & 0.97 & 1.43 & 1.38 \\
\hline & 12 & $4 \cdot 81^{\star \star \star}$ & 1.77 & 3.45 & 1.43 & $P \leq 0.01$ & $3.42^{\star \star *}$ & 1.43 & 1.96 & 1.95 \\
\hline \multirow[t]{2}{*}{$\sum n-6$ FA } & 0 & $34 \cdot 8$ & 3.92 & 34.4 & $4 \cdot 11$ & & $56 \cdot 0$ & $3 \cdot 77$ & $13 \cdot 3$ & $4 \cdot 15$ \\
\hline & 12 & 33.6 & 3.29 & 34.6 & 2.96 & $P \leq 0.01$ & $54 \cdot 8^{\star \star}$ & 4.07 & 11.7 & 4.21 \\
\hline \multirow[t]{2}{*}{$n-6: n-3$ ratio } & 0 & $12 \cdot 0$ & 3.20 & 11.4 & 2.34 & & 31.4 & $11 \cdot 6$ & $12 \cdot 6$ & $6 \cdot 28$ \\
\hline & 12 & $7 \cdot 87^{\star \star \star}$ & 2.96 & 11.4 & 3.89 & $P \leq 0.001$ & $18 \cdot 9^{\star \star \star}$ & 8.05 & $8 \cdot 81^{\star *}$ & $5 \cdot 32$ \\
\hline \multirow[t]{2}{*}{$\Sigma$ SFA } & 0 & $32 \cdot 0$ & 2.32 & $32 \cdot 1$ & $2 \cdot 16$ & & $14 \cdot 3$ & 1.40 & $26 \cdot 4$ & $5 \cdot 20$ \\
\hline & 12 & $32 \cdot 2$ & 1.89 & $31 \cdot 8$ & 1.99 & $P \leq 0.05$ & $14 \cdot 4$ & 1.47 & $25 \cdot 1$ & 8.36 \\
\hline \multirow{2}{*}{$\Sigma$ MUFA } & 0 & 25.5 & 2.57 & $25 \cdot 5$ & 2.68 & & 23.9 & 2.91 & 33.7 & 8.51 \\
\hline & 12 & 24.7 & 2.34 & $24 \cdot 7$ & 2.56 & NS & 23.5 & 2.93 & $37.6^{*}$ & $7 \cdot 87$ \\
\hline \multirow[t]{2}{*}{$\Sigma$ PUFA } & 0 & 38.4 & $4 \cdot 30$ & $38 \cdot 1$ & 4.35 & & $58 \cdot 3$ & $4 \cdot 16$ & $17 \cdot 2$ & 4.86 \\
\hline & 12 & 39.0 & 3.38 & 38.6 & 3.53 & NS & 58.5 & 4.33 & $15 \cdot 8$ & 3.52 \\
\hline \multirow[t]{2}{*}{$\Sigma$ CLA } & 0 & 0.61 & 0.10 & 0.62 & 0.16 & & 0.25 & 0.05 & $2 \cdot 29$ & 1.74 \\
\hline & 12 & 0.64 & 0.15 & 0.63 & 0.14 & NS & 0.22 & 0.08 & 2.04 & 1.35 \\
\hline
\end{tabular}

FAME, fatty acid methyl esters; ALA, $\alpha$-linolenic acid; AA, arachidonic acid; CLA, conjugated linoleic acids

Significantly different compared with the start value: ${ }^{\star} P \leq 0.05,{ }^{\star *} P \leq 0.01,{ }^{\star \star \star} P \leq 0.001$.

†Fatty acids were separated gas chromatographically as corresponding FAME.

$\ddagger$ End values are significantly different from the control period with baseline values as covariates.

Table 2. Consumption of chosen fatty acids (FA) by meat, meat products, fish, fish products, oils and fats (g FA/d)*

(Mean values and standard deviations)

\begin{tabular}{|c|c|c|c|c|c|}
\hline \multirow[b]{2}{*}{$n 21(\mathrm{~g} \mathrm{FA} / \mathrm{d})$} & \multicolumn{2}{|c|}{$\begin{array}{l}\text { Intervention } \\
\text { period }\end{array}$} & \multicolumn{2}{|c|}{$\begin{array}{l}\text { Control } \\
\text { period }\end{array}$} & \multirow{2}{*}{$\begin{array}{c}P_{\text {intervention }} \\
\text { period } v \text {. control period }\end{array}$} \\
\hline & Mean & $\mathrm{SD}$ & Mean & $\mathrm{SD}$ & \\
\hline Oleic acid & $12 \cdot 3$ & 18.5 & $13 \cdot 7$ & $26 \cdot 8$ & NS \\
\hline $\mathrm{AA}$ & 0.77 & 1.91 & 0.90 & 2.78 & NS \\
\hline EPA & 0.08 & 0.07 & 0.09 & 0.08 & NS \\
\hline $\mathrm{DHA}$ & 0.12 & 0.11 & 0.13 & 0.11 & NS \\
\hline$\sum n$-3 LC-PUFA & 0.24 & 0.20 & 0.26 & 0.22 & NS \\
\hline$n-3$ FA & $2 \cdot 61$ & 4.73 & $2 \cdot 79$ & $6 \cdot 33$ & NS \\
\hline$n-6$ FA & 5.85 & 7.45 & $5 \cdot 49$ & $8 \cdot 36$ & NS \\
\hline$n-6: n-3$ & $7 \cdot 57$ & 11.0 & $6 \cdot 82$ & $6 \cdot 40$ & NS \\
\hline Trans-FA & 0.16 & 0.10 & 0.17 & 0.10 & NS \\
\hline
\end{tabular}

AA, arachidonic acid; $n$-3 LC-PUFA, $n$-3 long-chain PUFA.

* Without the study products.

\section{Anthropometric data and clinical parameters}

There were no differences observed in the body weight, BMI, blood pressure, pulse rate, alkaline phosphatase and $\gamma$-glutamyltransferase in the intervention or the control period and between the end points of both the periods.

After $2 \times 12$ study weeks, there was a tendency for an increase in the body weight, BMI and the pulse rate. During this time, the diastolic blood pressure decreased significantly from 91 (SD17) to 84 (SD13) $\mathrm{mm} \mathrm{Hg}(P \leq 0 \cdot 01)$ and the alkaline phosphatase decreased significantly from 1.25 (SD $0.49) \mu \mathrm{mol} / \mathrm{l}$ to $1.16(\mathrm{SD} 0 \cdot 46) \mu \mathrm{mol} / \mathrm{l}(P \leq 0 \cdot 05)$.

\section{Blood lipids}

Total cholesterol was not affected by the intervention with dairy products (Table 3 ), although HDL increased significantly on consumption of dairy products rich in $n-3$ LC-PUFA. 
Table 3. Blood lipids, acute-phase reactants and disease activity at baseline and after a 12-week intake of $n-3$ long-chain PUFA ( $n$-3 LC-PUFA)-supplemented or control dairy products

(Mean values and standard deviations)

\begin{tabular}{|c|c|c|c|c|c|c|}
\hline \multirow[b]{2}{*}{$n 21$} & \multirow[b]{2}{*}{ Weeks } & \multicolumn{2}{|c|}{ Intervention period } & \multicolumn{2}{|c|}{ Control period } & \multirow[b]{2}{*}{$P_{\text {treatment effect }} \dagger$} \\
\hline & & Mean & SD & Mean & SD & \\
\hline \multirow[t]{2}{*}{$\mathrm{TC}(\mathrm{mmol} / \mathrm{l})$} & 0 & $5 \cdot 84$ & 0.90 & 5.75 & 0.78 & \\
\hline & 12 & $5 \cdot 83$ & 0.74 & $5 \cdot 76$ & 0.69 & NS \\
\hline \multirow[t]{2}{*}{$\mathrm{HDL}(\mathrm{mmol} / \mathrm{l})$} & 0 & 1.63 & 0.33 & 1.64 & 0.35 & \\
\hline & 12 & $1 \cdot 71^{\star}$ & 0.31 & 1.73 & 0.31 & NS \\
\hline \multirow[t]{2}{*}{$\mathrm{LDL}(\mathrm{mmol} / \mathrm{l})$} & 0 & $3 \cdot 82$ & 0.78 & 3.72 & 0.68 & \\
\hline & 12 & 3.80 & 0.73 & 3.82 & 0.74 & NS \\
\hline \multirow[t]{2}{*}{ LDL:HDL ratio } & 0 & 2.42 & 0.65 & $2 \cdot 34$ & 0.52 & \\
\hline & 12 & $2 \cdot 28$ & 0.58 & $2 \cdot 36$ & 0.61 & NS \\
\hline \multirow[t]{2}{*}{ Lp(a) (mg/l) } & 0 & 416 & 550 & 380 & 484 & \\
\hline & 12 & $326^{*}$ & 353 & 332 & 446 & NS \\
\hline \multirow{2}{*}{ TAG (mmol/l) } & 0 & $1 \cdot 11$ & 0.43 & $1 \cdot 13$ & 0.52 & \\
\hline & 12 & 1.00 & 0.41 & 1.32 & 1.28 & NS \\
\hline \multirow[t]{2}{*}{$\mathrm{CRP}(\mathrm{mg} / \mathrm{l})$} & 0 & $12 \cdot 2$ & 10.5 & $9 \cdot 81$ & 8.86 & \\
\hline & 12 & 14.4 & $14 \cdot 0$ & 7.74 & $4 \cdot 13$ & $P \leq 0.05^{*}$ \\
\hline \multirow[t]{2}{*}{ ESR (mm; $1 \mathrm{~h})$} & 0 & $22 \cdot 4$ & 20.4 & $17 \cdot 5$ & 11.1 & \\
\hline & 12 & $23 \cdot 8$ & $20 \cdot 0$ & $19 \cdot 4$ & 11.4 & NS \\
\hline \multirow[t]{2}{*}{ Duration of morning stiffness (min) } & 0 & $32 \cdot 7$ & $39 \cdot 8$ & $30 \cdot 1$ & $39 \cdot 8$ & \\
\hline & 12 & $25 \cdot 9$ & 29.3 & $20 \cdot 9$ & $23 \cdot 6$ & NS \\
\hline \multirow[t]{2}{*}{ No. of tender joints } & 0 & $7 \cdot 14$ & $6 \cdot 23$ & $6 \cdot 76$ & $7 \cdot 29$ & \\
\hline & 12 & $6 \cdot 52$ & $6 \cdot 15$ & $6 \cdot 71$ & 6.06 & NS \\
\hline \multirow[t]{2}{*}{ No. of swollen joints } & 0 & $4 \cdot 14$ & 2.85 & 4.33 & 2.96 & \\
\hline & 12 & 3.67 & 2.56 & 3.14 & 2.48 & NS \\
\hline \multirow[t]{2}{*}{ DAS28 } & 0 & 4.45 & 1.05 & $4 \cdot 18$ & 1.11 & \\
\hline & 12 & 4.32 & $1 \cdot 11$ & $4 \cdot 24$ & 0.80 & NS \\
\hline
\end{tabular}

TC, total cholesterol; Lp(a), lipoprotein a; CRP, C-reactive protein; ESR, erythrocyte sedimentation rate; DAS28, disease activity score 28.

* Significantly different compared with the start value $(P \leq 0 \cdot 05)$.

$\dagger$ End values are significantly different from the control period with baseline values as covariates.

The HDL increase in the control period was not significant. LDL and the LDL:HDL ratio remained unaffected by both the intervention and control treatments. In addition, supplementation with verum products was associated with significantly lower concentrations of lipoprotein a. In the intervention period, TAG values decreased from $1 \cdot 1$ (SD 0.4 ) to $1 \cdot 0$ (SD0.4) $\mathrm{mmol} / \mathrm{l}$ and, in the control period, the TAG concentrations increased. The end points of these study parameters showed no changes between the intervention and control treatments (Table 3).

Table 4. Immune markers and cyclo-oxygenase (COX) expression at baseline and after a 12-week intake of $n$-3 longchain PUFA-supplemented or control dairy products

(Mean values and standard deviations)

\begin{tabular}{|c|c|c|c|c|c|c|}
\hline \multirow[b]{2}{*}{$n 21$} & \multirow[b]{2}{*}{ Weeks } & \multicolumn{2}{|c|}{ Intervention period } & \multicolumn{2}{|c|}{ Control period } & \multirow[b]{2}{*}{$P_{\text {treatment effect }}$} \\
\hline & & Mean & SD & Mean & SD & \\
\hline \multirow[t]{2}{*}{ Lymphocytes ( $\mu$ l) } & 0 & 1677 & 743 & 1579 & 579 & \\
\hline & 12 & $1435^{\star *}$ & 554 & 1585 & 734 & NS \\
\hline \multirow[t]{2}{*}{ Monocytes ( $\mu \mathrm{l}$ ) } & 0 & 541 & 236 & 448 & 193 & \\
\hline & 12 & $418^{\star}$ & 201 & 410 & 177 & NS \\
\hline \multirow{2}{*}{ Granulocytes ( $\mu \mathrm{l})$} & 0 & 4682 & 2347 & 4241 & 1875 & \\
\hline & 12 & 4834 & 1994 & 4357 & 1749 & NS \\
\hline \multirow[t]{2}{*}{ Lymphocytes (\%) } & 0 & $25 \cdot 4$ & $10 \cdot 8$ & 25.5 & $10 \cdot 6$ & \\
\hline & 12 & $22 \cdot 8$ & 9.60 & 25.5 & $8 \cdot 80$ & $P \leq 0.05$ \\
\hline \multirow{2}{*}{ Monocytes (\%) } & 0 & 7.90 & $2 \cdot 19$ & 7.00 & 2.55 & \\
\hline & 12 & $6 \cdot 38^{\star *}$ & 2.56 & 6.57 & $2 \cdot 20$ & NS \\
\hline \multirow[t]{2}{*}{ Granulocytes (\%) } & 0 & $66 \cdot 6$ & $12 \cdot 0$ & 67.6 & 11.6 & \\
\hline & 12 & $70.9^{*}$ & 10.5 & 68.0 & 9.9 & $P \leq 0.05$ \\
\hline \multirow[t]{2}{*}{ COX-1 $1_{\text {unstimulated }}(\%)$} & 0 & 2.52 & 2.56 & $4 \cdot 20$ & $5 \cdot 11$ & \\
\hline & 12 & $4 \cdot 76^{\star}$ & 4.38 & 3.95 & 4.80 & NS \\
\hline \multirow[t]{2}{*}{ COX-2 $2_{\text {unstimulated }}(\%)$} & 0 & 2.43 & 2.96 & $4 \cdot 14$ & 4.02 & \\
\hline & 12 & 3.81 & 3.06 & 1.95 & 2.48 & $P \leq 0.01$ \\
\hline \multirow[t]{2}{*}{ COX-2 LPS stimulated $(\%)$} & 0 & 83.3 & $6 \cdot 27$ & $81 \cdot 2$ & $7 \cdot 65$ & \\
\hline & 12 & $77 \cdot 0^{\star \star}$ & 9.00 & 78.8 & $9 \cdot 87$ & NS \\
\hline
\end{tabular}

LPS, lipopolysaccharide.

Significantly different compared with the start value ${ }^{*} P \leq 0.05$, ${ }^{*} P \leq 0.01$.

$\dagger$ End values are significantly different from the control period with baseline values as covariates. 


\section{Immunological parameters and cyclo-oxygenase expression}

The following immunological parameters were not influenced by the consumption of $n$-3 LC-PUFA-supplemented dairy products: the concentration of granulocytes per $\mu \mathrm{l}$; the percentage of $\mathrm{CD} 3+, \mathrm{CD} 4+, \mathrm{CD} 8+, \mathrm{CD} 4+/ \mathrm{CD} 8+, \mathrm{NK}, \mathrm{CD} 3+\mathrm{HLA}-$ $\mathrm{DR}+, \mathrm{CD} 8+\mathrm{CD} 57+, \mathrm{CD} 25+, \mathrm{CD} 4+\mathrm{CD} 25+$ cells; as well as the degree of unstimulated COX-2 expression. However, there was a significant increase of granulocytes (percentage of leucocytes), CD19+ cells and COX-1 expression in the intervention period (Table 4; CD are not shown). Moreover, lymphocytes, monocytes, the lipopolysaccharide-stimulated COX-2 expression and $\mathrm{CD} 3+\mathrm{NK}+$ decreased significantly by the consumption of $n$-3 LC-PUFA-supplemented dairy products $(P \leq 0 \cdot 05)$.

In the control period, lymphocytes, monocytes, granulocytes, the percentage of $\mathrm{CD} 3+, \mathrm{CD} 19+, \mathrm{CD} 4+, \mathrm{CD} 8+, \mathrm{CD} 4+/ \mathrm{CD} 8+$, $\mathrm{NK}+, \mathrm{CD} 3+\mathrm{NK}+, \mathrm{CD} 3+\mathrm{HLA}-\mathrm{DR}+, \mathrm{CD} 25+, \mathrm{CD} 4+\mathrm{CD} 25+$ cells and the $\mathrm{COX}$-expression were not influenced. The numbers of CD57+ cells were significantly decreased $(P \leq 0 \cdot 01)$. The final values for granulocytes, CD8+, CD3+HLA-DR + and COX-2 expression (unstimulated) were significantly higher in the intervention period, whereas the final values of lymphocytes were higher in the control period $(P \leq 0 \cdot 05)$.

\section{Urinary parameters}

No differences in the $\mathrm{Pyr} / \mathrm{Cr}$, Dpyr/Cr concentrations and the Pyr:Dpyr ratio were observed in either the intervention or the control period, and between the end points of the intervention and control phases (Table 5). During the entire study period $(2 \times 12$ weeks $)$, $\mathrm{Pyr} / \mathrm{Cr}$ decreased significantly from 50.5 (SD 25.8) to 40.2 (SD 13.9) nmol $\mathrm{Pyr} / \mathrm{mmol} \mathrm{Cr}$ and Dpyr/Cr decreased significantly from 11.8 (SD 5.2) to $9 \cdot 1$ (SD 3.7) nmol Dpyr/mmol Cr $(P \leq 0 \cdot 05)$.

The urinary concentrations of 8-iso $\mathrm{PGF}_{2 \alpha}(\mathrm{nmol} / \mathrm{mmol} \mathrm{Cr})$, 15-keto-dihydro-PGF $2 \alpha(\mathrm{nmol} / \mathrm{mmol} \mathrm{Cr})$ and 8 -oxodG $(\mathrm{ng} / \mathrm{mg}$ $\mathrm{Cr} ; \mathrm{nmol} / 24 \mathrm{~h}$ per $\mathrm{kg}$ ) remained constant throughout the study.
No significant differences of the afore-mentioned parameters were noted between the start and final concentrations of both periods, between the end points of the treatment groups and for the entire term of the study time $(2 \times 12$ weeks; Table 5$)$.

\section{Acute-phase reactants and disease activity parameters}

C-reactive protein, erythrocyte sedimentation rate $(1 \mathrm{~h})$, the number of tender and swollen joints and the DAS28 did not change significantly during the intervention or control period. The duration of morning stiffness decreased in both periods, but not significantly (Table 3 ). Here, the end-point values of $\mathrm{C}$-reactive protein in the intervention period were significantly higher than in the control period $(P \leq 0.05)$.

The baseline values of DAS28 rested in one patient $<3.2$ $(\rightarrow$ inactive) in the intervention period. In fifteen patients, the baseline values were between $3 \cdot 2$ and $5 \cdot 1$ ( $\rightarrow$ active) and in five patients $>5 \cdot 1(\rightarrow$ highly active). Moreover, there was considerable improvement of the DAS28 in three patients $(14.3 \%)$, a moderate improvement in three patients $(14.3 \%)$, a moderate deterioration in four patients $(19.0 \%)$, a strong deterioration in one patient $(4.8 \%)$ and no changes in ten patients $(47.7 \%)$ in the intervention period.

In the control period, on the other hand, the DAS28 baseline values rested in five patients $<3 \cdot 2$, in twelve patients, they were between 3.2 and 5.1 and, in four patients, $>5 \cdot 1$.

In addition, a moderate improvement was seen in the control phase in one patient $(4.8 \%)$, a moderate deterioration in four patients $(19.0 \%)$, a strong deterioration in one patient $(4.8 \%)$ and no changes in fifteen patients $(47 \cdot 7 \%)$.

Correlation analysis of acute-phase reactants, disease activity score and urinary parameters

The baseline values of C-reactive protein correlated significantly with erythrocyte sedimentation rate $(r 0.381 * *)$ and

Table 5. Urinary biomarkers at baseline and after a 12-week intake of $n-3$ long-chain PUFA-supplemented or control dairy products

(Mean values and standard deviations)

\begin{tabular}{|c|c|c|c|c|c|c|}
\hline \multirow[b]{2}{*}{$n 21$} & \multirow[b]{2}{*}{ Weeks } & \multicolumn{2}{|c|}{$\begin{array}{l}\text { Intervention } \\
\text { period }\end{array}$} & \multicolumn{2}{|c|}{ Control period } & \multirow[b]{2}{*}{$P_{\text {treatment effect }} \dagger$} \\
\hline & & Mean & SD & Mean & SD & \\
\hline \multirow[t]{2}{*}{$\mathrm{Pyr} / \mathrm{Cr}(\mathrm{nmol} / \mathrm{mmol} \mathrm{Cr})$} & 0 & $51 \cdot 4$ & $27 \cdot 8$ & 43.5 & 13.0 & \\
\hline & 12 & 59.4 & 64.0 & 43.8 & 21.3 & NS \\
\hline \multirow[t]{2}{*}{ Dpyr/Cr (nmol/mmol Cr) } & 0 & $11 \cdot 6$ & $5 \cdot 26$ & $10 \cdot 9$ & 5.06 & \\
\hline & 12 & $16 \cdot 0$ & $19 \cdot 3$ & $10 \cdot 6$ & $5 \cdot 88$ & NS \\
\hline \multirow{2}{*}{ Pyr:Dpyr ratio } & 0 & 4.57 & 1.33 & 4.48 & 1.48 & \\
\hline & 12 & 4.04 & 1.22 & 4.48 & 1.35 & NS \\
\hline \multirow[t]{2}{*}{ 8-iso-PGF ${ }_{2 \alpha}(\mathrm{nmol} / \mathrm{mmol} \mathrm{Cr})$} & 0 & 0.35 & 0.18 & 0.40 & 0.12 & \\
\hline & 12 & 0.37 & 0.21 & 0.36 & 0.14 & NS \\
\hline \multirow[t]{2}{*}{ 15-keto-dihydro-PGF ${ }_{2 \alpha}(\mathrm{nmol} / \mathrm{mmol} \mathrm{Cr})$} & 0 & $0 \cdot 17$ & 0.11 & 0.19 & 0.07 & \\
\hline & 12 & 0.15 & 0.08 & 0.16 & 0.09 & NS \\
\hline \multirow[t]{2}{*}{ 8-OxodG (ng/mg Cr) } & 0 & 19.5 & 16.9 & $16 \cdot 1$ & $9 \cdot 86$ & \\
\hline & 12 & 22.4 & $15 \cdot 1$ & $20 \cdot 1$ & $17 \cdot 7$ & NS \\
\hline \multirow[t]{2}{*}{ 8-OxodG (nmol/24h per kg) } & 0 & 0.28 & 0.31 & 0.29 & 0.21 & \\
\hline & 12 & 0.31 & 0.27 & 0.30 & 0.34 & NS \\
\hline
\end{tabular}

$\mathrm{Pyr} / \mathrm{Cr}$, pyridinoline/creatinine; Dpyr/Cr, deoxypyridinoline/creatinine; 8-oxodG, 7,8-dihydro-8-oxo-2'-deoxyguanosine. $\dagger$ End values are significantly different from the control period with baseline values as covariates. 
DAS28 $(r ; P \leq 0.01 \quad 0 \cdot 389 * *)$. Erythrocyte sedimentation rate start values also correlated significantly with 8 -oxodG (nmol/24 her kg; $r$ 0.334; $P \leq 0.05$ ) and $\mathrm{Pyr} / \mathrm{Cr}(r \quad 0.320$; $P \leq 0.05)$. In addition, $\mathrm{Pyr} / \mathrm{Cr}$ correlated significantly with Dpyr/Cr $(r$ 0.722; $P \leq 0.01)$.

Furthermore, 8-iso- $\mathrm{PGF}_{2 \alpha}$ correlated significantly with 8-oxodG (nmol/24 h per kg; $r 0.376 ; P \leq 0.05$ ) and 15-keto-dihydro-PGF $2 \alpha$ ( $r$ 0.770; $P \leq 0.01)$. The baseline values of COX-1 correlated significantly with COX-2-unstimulated ( $r$ 0.544; $P \leq 0.01)$, 8-iso-PGF $2 \alpha(r \quad 0 \cdot 367 ; P \leq 0.01)$ and 15-keto-dihydro-PGF ${ }_{2 \alpha}(r 0.312 ; P \leq 0.01)$. Additionally, there were correlations between COX-2 unstimulated and Dpyr/Cr ( $r$ 0.239; $P \leq 0.05)$, 8-iso-PGF $2 \alpha(r 0.397 ; P \leq 0.01)$ and 15-keto-dihydro-PGF $2 \alpha(r 0.262 ; P \leq 0.05)$.

\section{Discussion}

\section{Changes in fatty acid distribution}

The FA analysis of plasma lipids, CE and PL from study subjects consuming dairy products supplemented with moderate doses of $n-3$ LC-PUFA over a long-term intervention showed a significant increase in EPA and DHA, leading to a decreased AA:EPA and AA:n-3 LC-PUFA ratio (Table 1). The change in the ratio of the eicosanoid precursory FA is favourable and indicates a reduction of $\mathrm{PG}$ and leukotriene formation from AA.

The results indicate a good compliance with the dairy products and a high bioavailability of the supplemented FA. Interestingly, EPA and DHA accumulated more slowly in PL than in total plasma lipids and CE. Similar results regarding the accumulation of EPA and DHA were found by Adam et al. ${ }^{(3)}$. Furthermore, the concentrations of $n-3$ FA and $n-6$ FA were lower in PL in comparison with that in total plasma lipids and CE. Particularly, the concentrations of EPA and AA were very low in PL (Table 1).

\section{Improvement in blood lipid values}

The baseline mean concentrations of HDL and TAG were within the normal range, though the total cholesterol, LDL and lipoprotein a levels were elevated compared with the reference values. Although, the consumption of verum products improved blood lipids, in the control group, the effects were weaker (Table 3). The baseline values of TAG were low in all patients. Perhaps if TAG values would have been elevated, the observed TAG-lowering effect of n-3 LCPUFA supplementation might be more pronounced. These results confirm the TAG-lowering effect of $n-3$ LC-PUFA described in previous studies and reviews ${ }^{(4,25-29)}$.

Moreover, out results suggest an atherosclerosis-preventive and, thus, cardioprotective effect of long-term consumption of dairy products via the modulation of blood lipids and other cardiovascular risk factors. RA patients have a higher risk of CVD because of a deteriorated vascular function and a prolonged elevation of C-reactive protein values ${ }^{(30-34)}$. Hence, inhibiting the primary development and a subsequent progression of CVD by means of controlling the risk factors is particularly important for RA patients.

The results of many studies indicated that the intake of high quantities of $n$-3 LC-PUFA can make a contribution towards the prevention of $\mathrm{CVD}^{(4,35-39)}$. In the present study, the consumption of dairy products supplemented with moderate doses of $n$-3 LC-PUFA improved cardiovascular risk factors to a similar degree achieved in other studies using high doses of $n$-3 LC-PUFA.

Influences on immunological parameters and cyclo-oxygenase expression

All immunological parameters were within the normal range, except the fact that the mean values of $\mathrm{CD} 3+\mathrm{NK}+, \mathrm{CD} 25+$ and $\mathrm{CD} 4+\mathrm{CD} 25+$ were elevated compared with the reference values. The bulk of the analysed CD, e.g. T-cells and T-helper cells (CD3+ and CD4+), was not affected through the consumption of $n-3$ LC-PUFA-supplemented dairy products. However, the effects on lymphocytes, monocytes (Table 4) and $\mathrm{CD} 3+\mathrm{NK}+$ (cytotoxic T-cells) were beneficial. It can be concluded that the intake of $n$-3 LC-PUFA-supplemented dairy products suppresses the specific and unspecific immune responses and, possibly, contributes to a reduction of the inflammatory process.

In the present study, $n$-3 LC-PUFA influenced COX expression in the whole-blood monocytes by increasing COX-1 and decreasing lipopolysaccharide-stimulated COX-2 (Table 4). Since COX-1 is not inducible by external stimuli under both physiological and pathological conditions ${ }^{(40)}$, the significant increase of COX-1 cannot be the result of $n-3$ LC-PUFA supplementation. By contrast, COX-2 expression can be induced by various stimuli, e.g. cellular stress and inflammatory cytokines ${ }^{(41,42)}$. The COX-2 overexpression leads to an increase in $\mathrm{PGE}_{2}$ biosynthesis and angiogenesis, further mediating inflammation and mitogenesis ${ }^{(43,44)}$. In the present study, the COX-2 expression induced by bacterial lipopolysaccharide was diminished by $n-3$ LC-PUFA (Table 4). Similarly, $n-3$ LC-PUFA could also reduce COX-2 expression induced by other stimuli. This is in accordance with the previous data that show a reduction of COX-2 expression by $n-3$ LC-PUFA $^{(45-47)}$. In summary, inflammatory mediators, such as COX-2 and $\mathrm{PGE}_{2}$, that are involved not only in the pathogenesis of degenerative joint diseases, but also in that of inflammatory joint diseases are reduced by $n-3$ LC-PUFA supplementation.

Thus, $n-3$ LC-PUFA act as selective COX-2 inhibitors. Furthermore, these innovative dairy products possibly support non-steroidal anti-inflammatory drugs or glucocorticoid therapy in RA patients. Side effects of non-steroidal antiinflammatory drugs such as gastric lesions and renal toxicity are associated with the inhibition of $\mathrm{COX}-1^{(48)}$. In this regard, the increase in $\mathrm{COX}-1$ expression despite the fact that seventeen of the study patients took a daily dose of non-steroidal anti-inflammatory drugs can be interpreted as a positive result.

\section{Effects on hydroxypyridinium crosslinks}

The baseline values of urinary collagen crosslinks were elevated in RA patients compared with the reference values (Table 5). These results were found to be in agreement with the data of previous studies ${ }^{(21,50,51)}$. An increased crosslink excretion reflects an increased turnover and degradation of articular cartilage, as well as an increased bone resorption ${ }^{(52,53)}$. 
The correlations between the urinary crosslinks, inflammation markers and disease activity in the present study and from the previous data ${ }^{(51,5455)}$ substantiate an association between rheumatic inflammation processes and collagen degradation.

Thus, the long-term consumption of dairy products prevents cartilage and bone resorption in RA patients, which is indicated by a decrease in the $\mathrm{Pyr} / \mathrm{Cr}$ and $\mathrm{Dpyr} / \mathrm{Cr}$ excretion designated by the normal end values recorded in the study.

\section{Parameters of oxidative stress and inflammation}

The urinary concentrations of 8-iso $\mathrm{PGF}_{2 \mathrm{a}}$ and 15-keto-dihydro$\mathrm{PGF}_{2 \mathrm{a}}$ were not significantly altered by the intervention (Table 5). The major $\mathrm{F}_{2}$-isoprostanes 8 -iso- $\mathrm{PGF}_{2 \alpha}$ is a reliable biomarker for in vivo measurement of lipid peroxidation. It is derived from AA using non-enzymatic free-radical-induced peroxidation and oxidative stress $^{(22,56)} .15-$ Keto-dihydro-PGF ${ }_{2 \alpha}$ is a major metabolite of $\mathrm{PGF}_{2 \alpha}$ and serves as an inflammation marker that indicates COX-2-dependent lipid peroxidation ${ }^{(23)}$. A strong correlation between oxidative injury (8-iso- $\mathrm{PGF}_{2 \alpha}$ ) and inflammation response (15-keto-dihydro- $\left.\mathrm{PGF}_{2 \alpha}\right)$ was also found by Basu et al. ${ }^{(57)}$. Oxidative injury is an important mechanism involved in the chronic inflammatory state in rheumatic patients $^{(57,58)}$. Possibly, an increased consumption of PUFA can be associated with a higher oxidative stress and a rise in lipid peroxides ${ }^{(58)}$. However, other investigations have shown a significant decrease of 8 -iso- $\mathrm{PGF}_{2 \alpha}$ after intervention with $n-3$ PUFA $^{(59,60)}$. The study results also indicate that the consumption of moderate doses of $n-3$ LC-PUFA does not lead to an increase in oxidative injury (Table 5). The 8-iso- $\mathrm{PGF}_{2 \alpha}$ and 15-keto-dihydro- $\mathrm{PGF}_{2 \alpha}$ concentrations determined in RA patients (Table 5) are comparable with concentrations in healthy subjects ${ }^{(24)}$.

8-OxodG, induced by reactive oxygen species, is a biomarker of promutagenic DNA lesions ${ }^{(61)}$. In the present study, the urinary 8-oxodG concentrations of RA patients were strongly elevated in comparison with healthy subjects $\left(\right.$ Table 5) ${ }^{(24)}$. Furthermore, elevated concentrations of 8-oxodG were found in lymphocytes and synovial fluid of RA patients ${ }^{(61,62)}$. An increased inflammation-related production of reactive oxygen species may explain the elevated 8 -oxodG values in RA patients. Our result indicates that the consumption of moderate doses of $n$-3 LC-PUFA causes no additional DNA damage (Table 5).

\section{Influence on clinical symptoms}

In the present study, an influence of $n-3$ LC-PUFAsupplemented dairy products on clinical symptoms or inflammation markers was not evident. A few previously published studies and reviews have shown potentially therapeutic benefits of $n$-3 LC-PUFA in RA patients ${ }^{(3,12,63)}$. The consumption of $n$-3 LC-PUFA-supplemented dairy products diminished the disease activity in only a small number of our patients correlating with the data from other studies ${ }^{(13,14)}$. The values of C-reactive protein remained largely unaltered in other investigations with $n-3$ LC-PUFA $^{(3,64)}$. This low effect of $n$-3 LC-PUFA supplementation on disease activity and acute-phase reactants could be accounted for the unaltered AA concentrations observed in plasma lipids, CE and PL due to an unlimited AA intake in the present study and the continuous AA intake with the study products. The results indicated that the limitation of AA intake might be the precondition for the anti-inflammatory effects and the benefit for RA patients through the consumption of $n-3$ LC-PUFA.

\section{Conclusions}

The consumption of dairy products enriched with moderate doses of $n$-3 LC-PUFA improves blood lipids, suppresses the immune response and reduces the lipopolysaccharidestimulated COX-2 expression. Additionally, a long-term consumption of dairy products prevents elevated cartilage and bone resorption in RA, indicated by decreased excretion of hydroxypyridinium crosslinks. Finally, the intake of moderate doses of $n$-3 LC-PUFA over a long period does not induce oxidative injury, lipid peroxidation or DNA damage.

\section{Acknowledgements}

The present study was supported by a grant from the German Federal Ministry of Education and Research (BMBF). C. D., R. S. and G. J. were involved in the study design. C. D. was responsible for the conduct of the study, data acquisition, statistical analysis and for producing the manuscript. C. D. and G. J. were responsible for data interpretation and critical revision of the manuscript. R. S. was in charge of obtaining the funding and G. H. and T. E. were responsible for medical care of the study patients. C. D., A. M. and S. B. performed the experimental work. G. J. supervised the present work. None of the authors had any personal or financial conflicts of interest. Special thanks go to the HERZGUT ${ }^{\mathrm{TM}}$ creamery for creating and allocating the study products.

\section{References}

1. James MJ \& Cleland LG (1997) Dietary $n-3$ fatty acids and therapy for RA. Semin Arthritis Rheu 27, 85-97.

2. Holub BJ (2002) Clinical Nutrition 4. Omega-3 fatty acids in cardiovascular care. Can Med Assoc J 166, 608-615.

3. Adam O, Beringer C, Kless T, et al. (2003) Anti-inflammatory effects of low arachidonic acid diet and fish oil in patients with rheumatoid arthritis. Rheumatol Int $\mathbf{2 3}, 27-36$.

4. Holub DJ \& Holub BJ (2004) Omega-3 fatty acids from fish oils and cardiovascular disease. Mol Cell Biochem 263, 217-225.

5. Breslow JL (2006) $n$-3 Fatty acids and cardiovascular disease. Am J Clin Nutr 83, 1477-1482.

6. Calder PC (1997) n-3 Polyunsaturated fatty acids and cytokine production in health and disease. Ann Nutr Metab 41, 203-234.

7. Calder PC (2002) Dietary modification of inflammation with lipids. Proc Nutr Soc 61, 345-358.

8. Adam O (2003) Dietary fatty acids and immune reactions in synovial tissue. Eur J Med Res 8, 381-387.

9. Simopoulos AP (2001) Evolutionary aspects of diet, essential fatty acids and cardiovascular diseases. Eur Heart J Suppl 3, $8-21$.

10. Volker DH, Fitzgerald PEB \& Garg ML (2000) The eicosapentaenoic to docosahexaenoic acid ratio of diets affects the pathogenesis of arthritis in LEW/SSN rats. $J$ Nutr 130, 559-565.

11. Cleland LG, James MJ \& Proudman SM (2003) The role of fish oil in the treatment of rheumatoid arthritis. Drugs 63, $845-853$. 
12. Kremer JM, Lawrence DA, Jubiz W, et al. (1990) Dietary fish oil and olive oil supplementation in patients with rheumatoid arthritis. Clinical and immunologic effects. Arthritis Rheum 33, 810-820.

13. Geusens P, Woulters C, Nijs J, et al. (1994) Long-term effect of omega-3 fatty acid supplementation in active rheumatoid arthritis. A 12-month, double-blind, controlled study. Arthritis Rheum 37, 824-829.

14. Volker D, Fitzgerald P, Major G, et al. (2000) Efficiancy of fish oil concentrate in the treatment of rheumatoid arthritis. J Rheumatol 27, 2343-2346.

15. Jaudszus A, Foerster M, Kroegel C, et al. (2005) Cis-9,trans11-CLA exerts anti-inflammatory effects in human bronchial epithelial cells and eosinophils: Comparison to trans-10, cis-12-CLA and to linoleic acid. Biochim Biophys Acta 1737, 111-118.

16. Jaudszus A, Krokowski M, Möckel P, et al. (2008) Cis 9,trans 11-conjugated linoleic acid inhibits allergic sensitization and airway inflammation via a PPAR $\gamma$-related mechanism in mice, $J$ Nutr (In the Press).

17. Blight EG \& Dyer WJ (1959) A rapid method of total lipid extraction and purification. Can J Biochem Physiol 37, 911-917.

18. Klein A, Friedrich U, Vogelsang H, et al. (2007) Lactobacillus acidophilus 74-2 and Bifidobacterium animalis subsp lactis DGCC 420 modulate unspecific cellular immune response in healthy adults. Eur J Clin Nutr 38, 93-102.

19. Ruitenberg JJ \& Waters CA (2003) A rapid flow cytometric method for detection of intracellular cyclooxygenases in human whole blood monocytes and COX-2 inducible human cell line. J Immun Meth 274, 93-104.

20. Mueller A, Hein G, Franke S, et al. (1996) Quantitative analysis of pyridinium crosslinks of collagen in the synovial fluid of patients with rheumatoid arthritis using high-performance liquid chromatography. Rheumatol Int 16, 23-28.

21. Hein G, Franke S, Mueller A, et al. (1997) The determination of pyridinium crosslinks in urine and serum as a possible marker of cartilage degradation in rheumatoid arthritis. Clin Rheumatol 16, 167-172.

22. Basu S (1998) Radioimmunoassay of 8-iso-prostaglandin $F_{2 \alpha}$ : an index for oxidative injury via free radical catalysed lipid peroxidation. Postaglandins Leukot Essent Fatty Acids 58, 319-325.

23. Basu S (1998) Radioimmunoassay of 15-keto-13,14-dihydroprostaglandin $\mathrm{F}_{2 \alpha}$ : an index for inflammation via cyclooxygenase catalysed lipid peroxidation. Postaglandins Leukot Essent Fatty Acids 58, 347-352.

24. Kuhnt K, Wagner A, Kraft J, et al. (2006) Dietary supplementation with 11trans- and 12trans-18:1 and oxidative stress in humans. Am J Clin Nutr 84, 981-988.

25. Schacky C (2000) $n$-3 Fatty acids and the prevention of coronary atherosclerosis. Am J Clin Nutr 71, 224-227.

26. Park Y \& Harris WS (2003) Omega-3 fatty acid supplementation accelerates chylomicron triglyceride clearance. J Lipid Res 44, 455-463.

27. Singer P \& Wirth M (2003) Omega-3-Fettsäuren marinen und pflanzlichen Ursprungs: Versuch einer Bilanz. ErnährungsUmschau 50, 296-297.

28. Smith B, Sun GY, Donahue OM, et al. (2004) Exercise plus $n-3$ fatty acids: additive effect on postprandial lipemia. Metabolism 53, $1365-1371$.

29. Milte CM, Coates AM, Buckley JD, et al. (2007) Dose-dependent effects of docosahexaenoic acid-rich fish oil on erythrocyte docosahexaenoic acid and blood lipid levels. Br J Nutr 31, 1-6.

30. Wolfe F, Mitchell DM, Sibley JT et al. (1994) The mortality of rheumatoid arthritis. Arthritis Rheum 37, 481-494.

31. Speidl WS, Graf S, Hornykewycz S, et al. (2002) High-sensitivity $\mathrm{C}$-reactive protein in the prediction of coronary events in patients with premature coronary artery disease. Am Heart $J$ 144, 449-455.

32. Ridker PM, Rifai N, Rose L, et al. (2002) Comparison of Creactive protein and low density lipoprotein cholesterol levels in the prediction of first cardiovascular events. $N$ Engl J Med 347, 1557-1565.

33. Del Rincón I, Williams K, Stern MP, et al. (2003) Association between carotid arteriosclerosis and markers of inflammation in rheumatoid arthritis patients and healthy subjects. Arthritis Rheum 48, 1833-1840.

34. Wong M, Toh L, Wilson A, et al. (2003) Reduced arterial elasticity in rheumatoid arthritis and the relationship to vascular disease risk factors and inflammation. Arthritis Rheum 48, 81-89.

35. Demaison L \& Moreau D (2002) Dietary $n-3$ polyunsaturated fatty acids and coronary heart disease-related mortality: a possible mechanism of action. CMLS 59, 463-477.

36. Hu FB, Bronner L \& Willett WC (2002) Fish and omega-3 fatty acid intake and risk of coronary heart disease in women. $J$ Am Med Assoc 287, 1815-1821.

37. Kris-Etherton PM, Harris WS \& Appel LJ (2002) Fish consumption, fish oil, omega-3 fatty acids, and cardiovascular disease. Circulation 106, 2747-2757.

38. Mozaffarin D, Ascherio A, Hu FB, et al. (2005) Interplay between different polyunsaturated fatty acids and risk of coronary heart disease in men. Circulation 111, 157-164.

39. Hjerkinn EM, Seljeflot I, Ellingsen I, et al. (2005) Influence of long-term intervention with dietary counselling, long chain $n-3$ fatty acid supplements, or both on circulation markers of endothelial activation in men with long-standing hyperlipidemia. Am $J$ Clin Nutr 81, 583-589.

40. Tapiero H, Nguyen BG, Couvreur P, et al. (2002) Polyunsaturated fatty acids (PUFA) and eicosanoids in human health and pathologies. Biomed Pharmacother 56, 215-222.

41. Smith WL, Garavito RM \& DeWitt DL (1996) Prostaglandin endoperoxide $\mathrm{H}$ synthases (cyclooxygenases)-1 and -2. J Biol Chem 271, 33157-33160.

42. Maloney CG, Kutchera WA, Albertine KH, et al. (1998) Inflammatory agonists induce cyclooxygenase type 2 expression by human neutrophils. J Immunol 160, 1402-1410.

43. Daniel TO, Liu H, Morrow JD, et al. (1999) Thromboxane A2 is a mediator of cyclooxygenase-2-dependent endothelial migration and angiogenesis. Cancer Res 59, 4574-4577.

44. Patrignani P, Panara MR, Greco A, et al. (1994) Biochemical and pharmacological characterization of the cyclooxygenase activity of human blood prostaglandin endoperoxide synthases. J Pharmacol Exp Ther 271, 1705-1712.

45. Mantzioris E, Cleland LG, Gibson RA, et al. (2000) Biochemical effects of a diet containing foods enriched with $n-3$ fatty acids. Am J Clin Nutr 72, 42-48.

46. Denkins Y, Kempf D, Ferniz M, et al. (2005) Role of $n$-3 polyunsaturated fatty acids on cyclooxygenase-2 metabolism in brain-metastatic melanoma. J Lipid Res 46, 1278-1284.

47. Horia E \& Watkins BA (2007) Complementary actions of docosahexaenoic acid and genistein on COX-2, PGE2, and invasiveness in MDA-MB-231 breast cancer cells. Carcinogenesis 28, 809-815.

48. Bombardier C, Laine L, Reicin A, et al. (2000) Comparison of upper gastrointestinal toxicity of Rofecoxib and Naproxen in patients with rheumatoid arthritis. NEngl J Med 343, 1520-1528.

49. Rodriguez GLA \& Barreales TL (2007) Risk of upper gastrointestinal complications among users of traditional NSAIDs and COXIBs in the general population. Gastroenterology 132, 498-506.

50. Spector TD, James IT, Hall GM, et al. (1993) Increased levels of urinary collagen crosslinks in females with rheumatoid arthritis. Clin Rheumatol 12, 240-244. 
51. Kollerup G, Hansen M \& Horslev-Petersen K (1994) Urinary hydroxypyridinium crosslinks of collagen in rheumatoid arthritis. Relation to disease activity and effects of methylprednisolone. Br J Rheumatol 33, 816-820.

52. Robins SP, Duncan A, Wilson N, et al. (1996) Standardization of pyridinium crosslinks, pyridinoline, for use as biochemical markers of collagen degradation. Clin Chem 42, 1621-1626.

53. Takahashi M, Kushida K, Hoshino H, et al. (1996) Concentrations of pyridinoline and deoxypyridinoline in joint tissues from patients with osteoarthritis or rheumatoid arthritis. Ann Rheum Dis 55, 324-327.

54. Bölzer C, Müller A, Bräunig E, et al. (2003) Kollagenabbauaktivität bei Spondylitis ankylosans in Beziehung zu krankheitsrelevanten Daten. Z Rheumatol 62, 459-467.

55. Kaufmann J, Mueller A, Voigt A, et al. (2003) Hydroxypyridinium collagen crosslinks in serum, urine, synovial fluid and synovial tissue in patients with rheumatoid arthritis compared with osteoarthritis. Rheumatology 42, 314-320.

56. Quaggiotto P, Leitch JW, Falconer J, et al. (2000) Plasma F2a-isoprostane levels are lowered in pigs fed a $(n-3)$ polyunsaturated fatty acid supplemented diet following occlusion of the left anterior descending coronary artery. Nutr Res 20, 675-684.

57. Basu S, Whiteman M, Mattey DL, et al. (2001) Raised levels of F2-isoprostanes and prostaglandin F2a in different rheumatic diseases. Ann Rheum Diss 60, 627-631.
58. Halliwell B \& Chirico S (1993) Lipid peroxidation: its mechanisms, measurement, and significance. Am J Clin Nutr 57, $715-725$.

59. Higdon JV, Liu J, Du SH, et al. (2000) Supplementation of postmenopausal woman with fish oil rich in eicosapentaenoic acid and docosahexaenoic acid is not associated with greater in vivo lipid peroxidation compared with oils rich in oleate and linoleate as assessed by plasma malondialdehyde and $\mathrm{F}(2)$-isoprostanes. Am J Clin Nutr 72, 714-722.

60. Nälsen C, Vessby B, Berglund L, et al. (2006) Dietary (n-3) fatty acids reduce plasma F2-isoprostanes but not prostaglandin F2a in healthy humans. J Nutr 136, 1222-1228.

61. Bashir S, Harris G, Denman MA, et al. (1993) Oxidative DNA damage and cellular sensitivity to oxidative stress in human autoimmune diseases. Ann Rheum Diss 52, 659-666.

62. Hajizadeh S, DeGroot J, TeKoppele JM, et al. (2003) Extracellular mitochondrial DNA and oxidatively damaged DNA in synovial fluid of patients with rheumatoid arthritis. Arthritis Res Ther 5, 234-240.

63. Cleland LG, Proudman SM, Hall C, et al. (2003) A biomarker of $n-3$ compliance in patients taking fish oil for rheumatoid arthritis. Lipids 38, 419-424.

64. Madsen T, Christensen JH \& Schmidt EB (2007) C-reactive protein and $n-3$ fatty acids in patients with a previous myocardial infarction. Eur J Nutr 46, 428-430. 